\title{
POR UMA EDUCAÇÃO PARA ALÉM DA CIDADANIA: $O$ caso de Rio Bonito do Iguaçu (de 1980 a 2007)
}

\author{
Cláudia Regina Paese ${ }^{1}$ \\ Universidade Federal do Mato Grosso (UFMT) \\ Paulino José Orso ${ }^{2}$ \\ Universidade Estadual do Oeste do Paraná (UNIOESTE)
}

\section{RESUMO}

Neste artigo se pretende realizar uma reflexão sobre a educação do/no campo, tendo presente a experiência do Rio Bonito do Iguaçu, ocorrida no período entre 1980 e 2007. Para isso, traz à tona os movimentos sociais do campo, que têm na educação uma importante bandeira de suas luta. Marcados pelas práticas de cooperação e solidariedade que vivenciam, procuram idealizar projetos sociais mais avançados do que os fundados nas formais liberdade e igualdade em que se assenta a cidadania burguesa. Deste modo, os movimentos populares também procuram ampliar o horizonte da educação para além da cidadania.

Palavras-chaves: Educação e cidadania; Educação e Emancipação; Rio Bonito do Iguaçu.

\section{EDUCATION FOR CITIZENSHIP BEYOND:} The case of Rio Bonito do Iguaçu (1980-2007).

\begin{abstract}
This article intends to undertake a reflection on the education field, bearing in mind the experience of the Rio Bonito do Iguaçu, in the period between 1980 and 2007. For this, brings out the social movements, which have an important flag in the education of their struggle. Characterized by practices of cooperation and solidarity that experience, seek to idealize social projects more advanced than those based on formal freedom and equality upon which rests the bourgeois citizenship. Thus, the popular movements also seek to broaden the horizon of education beyond citizenship.
\end{abstract}

Keywords: Education and citizenship; Education and Emancipation; Rio Bonito do Iguaçu.

\section{Educação para além da cidadania}

Neste artigo se pretende realizar uma reflexão sobre a educação do/no campo, tendo presente a experiência do Rio Bonito do Iguaçu, ocorrida no período entre 1980 e 2007. Para isso, traz à tona os movimentos sociais do campo, que têm na educação uma de suas importantes bandeiras luta. Marcados pelas práticas de cooperação e solidariedade que vivenciam, procuram idealizar projetos sociais mais avançados do que os fundados nas formais liberdade e igualdade em que se assenta a cidadania burguesa. Deste modo, os movimentos populares também procuram ampliar o horizonte da educação para além da cidadania.

A história dos trabalhadores do campo, suas lutas pela terra e pela educação estão vinculadas às profundas transformações que têm ocorrido no mundo do trabalho, o que significa falar do capitalismo em sua fase mais recente e das novas relações que se estabelecem entre o Estado e a Sociedade. 
Estabelecem-se novas relações entre trabalho, ciência e cultura, a partir das quais se constitui historicamente um novo princípio educativo, ou seja, um novo projeto pedagógico através do qual a sociedade pretende formar os intelectuais/trabalhadores, os cidadãos/produtores para atender às novas demandas postas pela globalização da economia e pela reestruturação produtiva. $\mathrm{O}$ velho princípio educativo, decorrente da base técnica da produção taylorista/fordista vai sendo substituído por outro projeto pedagógico determinado pelas mudanças ocorridas no trabalho, o qual, embora ainda não hegemônico, começa a apresentar-se como dominante. (KUENZER, 1985, p. 55).

Nesta perspectiva os trabalhadores do campo acreditarem que a conquista da terra só pode ser alcançada por meio da formação do sujeito social. Assim, tomam a educação como uma significativa bandeira de luta. Vendramini (2000, p. 162), destaca que

[...] a educação, à medida que cumpre sua função de difundir saberes e comportamentos, que se podem desdobrar em práticas as quais visam às mudanças sociais, de acordo com as necessidades dos movimentos, é um importante instrumento de conscientização, que pode contribuir para diminuir a distância entre o que a direção do MST proclama e a noção que orienta a sua ação.

Contudo, se por um lado, a educação no campo estabelece um diálogo com a teoria pedagógica a partir da realidade particular dos camponeses, por outro, preocupa-se com a formação humana no seu conjunto.

As possibilidades de uma efetiva emancipação humana ainda podem encontrar concretude e viabilidade social a partir das revoltas e rebeliões que se originam centralmente no mundo do trabalho; um processo de emancipação simultaneamente do trabalho, no trabalho e pelo trabalho. Essa rebeldia e contestação não excluem nem suprime outras, igualmente importantes. Mas, vivendo numa sociedade que produz mercadorias, valores de troca, as revoltas do trabalho acabam tendo estatuto de centralidade. (ANTUNES, 2001, p. 216).

Um dos traços fundamentais do movimento por uma educação do campo é a luta por políticas públicas que garantam o direito à educação, uma educação que seja no e do campo. No campo: significa que o povo tem direito a ser educado no lugar onde vive; do campo: significa que tem direito a uma educação pensada desde o seu lugar, com a sua participação, vinculada à sua cultura e às suas necessidades humanas e sociais (CALDART, 1997).

De um lado, as lutas pela posse da terra passam pelas relações entre os latifundiários e o Estado, que não são uma exclusividade de nosso tempo. São, isso sim, uma das marcas históricas do desenvolvimento e do processo de ocupação do campo. De outro, temos os vários movimentos sociais do campo que lutam pela conquista da terra, onde aparece com destaque o Movimento dos Trabalhadores Rurais Sem Terra (MST), que em 1985, protagonizou uma das maiores ocupações de terra já ocorridas no Brasil. O episódio ocorreu na Fazenda Sarandi, localizada no município do mesmo nome, no Rio Grande do Sul, no qual havia mais de mil e quinhentas pessoas acampadas. 
Naquele momento o governo estadual gaúcho do então governador Leonel Brizola, buscava reverter uma ocupação ilegal de terras de uma reserva indígena Kaigang realizada nos anos 1960, para fins de reforma agrária. Com o objetivo de reassentar os índios, expulsou os camponeses do assentamento na localidade conhecida como Encruzilhada Natalino. Como reação, os agricultores deslocados decidiram, espontaneamente, ocupar a vizinha Fazenda Anonni. (MORISSAWA, 2001, p. 32).

No início da década de 1980, depois deu um período de gestação entre 1979 e 1984, foi criado formalmente o MST, associado à Comissão Pastoral da Terra (CPT), à Central Única dos Trabalhadores (CUT) e ao Partido dos Trabalhadores (PT) ${ }^{3}$, durante o Primeiro Encontro Nacional de Trabalhadores Sem Terra, ocorrido entre 21 a 24 de janeiro de 1984, em Cascavel, no Estado do Paraná.

O MST tem suas origens nos conflitos agrários do final dos anos setenta, ainda em plena ditadura militar, quando camponeses sem-terra resistiam às propostas governamentais de colonização e reforma agrária - na verdade, apenas de colonização uma vez que não se tinha a intenção de mudar a estrutura fundiária do país - e lutavam pelo direito constitucional à terra em seus próprios estados. (PEREIRA, 2003, p.6).

Portanto, o surgimento do MST ocorreu no fim da ditadura militar, coincidindo com a abertura política e o início do processo de redemocratização no país (PEREIRA, 2003, p.6). Nasceu da articulação das lutas pela terra, especialmente na região centro-sul do país e aos poucos se expandiu pelo Brasil.

Sem Terra, com letras maiúsculas e sem hífen, é o nome próprio que identifica os sem-terra do MST. A expressão 'sem-terra' indica a categoria social de trabalhadores e trabalhadoras do campo que não têm terra e que passam a requerê-la como direito. Trata-se de um vocábulo recente nos dicionários de língua portuguesa, que expressa uma realidade de conflito, de luta pela posse da terra e pela libertação. De acordo com (MELO, 2003, p.113) "[...] o MST surge em nosso cenário político e econômico propondo-se a lutar por mudanças sociais no país e pela construção de uma sociedade sem exploradores e explorados".

Nos anos 1990, o movimento redefine suas estratégias e insere-se numa economia de mercado, objetiva tornar os assentamentos mais produtivos, voltados para o mercado e não mais apenas para o consumo de subsistência.

Neste contexto, a escola passa a representar para o movimento sua trajetória de luta, a história de seus integrantes; atribui-se a ela fazer a diferença para uma vida futura (MORISSAWA, 2001). Isso fica claro quando da construção do projeto político pedagógico do MST em que se define escola do campo.

[...] entende-se por escola do campo aquela que trabalha desde os interesses, a política, a cultura e a economia dos diversos grupos de trabalhadores e trabalhadoras do campo, nas suas diversas formas de trabalho e de organização, na sua dimensão de permanência de processo, produzindo valores, conhecimento, tecnologias na perspectiva do desenvolvimento social e econômico igualitário dessa população. A identificação política e a inserção geográfica na própria realidade cultural do campo são condições fundamentais de sua implementação. (KOLLING; NERY; MOLINA, 1999, P. 63). 
Ou seja, MST propõe-se a tomar para si a direção da educação e realizar uma educação para além das estruturas escolares instituídas, afirmar uma alternativa à educação voltada aos interesses do capital. Assim pretende implementar um projeto de educação em que o conteúdo escolar reflita o processo de formação humana que se constrói com referências culturais e políticas do campo, em que possa pensar o campo no contexto do modelo capitalista de desenvolvimento, porém tendo em vista sua superação.

\section{Educação básica para o campo}

Com o reaparecimento de movimentos sociais no campo, a partir de 1980 e com as mudanças que ocorrem na sociedade, a escola rural também ganha novo sentido, não apenas pelas exigências de atendimento às crianças e aos jovens. Instala-se um debate sobre o sentido da escola, sobre seu caráter formativo, sobre a formação de professores e o aprendizado que deve se efetivar. Com isso, o Movimento dos Trabalhadores Rurais Sem Terra toma frente às discussões educativas no campo e desenvolve uma nova proposta de educação e de formação de educadores.

O MST, como organização social de massas, decidiu, pressionado pela mobilização das famílias e das professoras, tomar para si ou assumir a tarefa de organizar e articular por dentro de sua organicidade esta mobilização, assumir uma proposta pedagógica específica para as escolas conquistadas, e formar educadores e educadoras capazes de trabalhar nesta perspectiva. A criação de um Setor de Educação dentro do MST formaliza o momento em que esta tarefa foi intencionalmente assumida. Isso aconteceu em 1987. (CALDART, 1995, p. 62).

O Movimento reflete sobre o papel das escolas rurais e procura realizar um processo educativo combinando a apropriação de conhecimentos teóricos com as lutas, ocupações, acampamentos, caminhadas, atos públicos e organização dos assentamentos, de tal forma que a educação adquire uma conotação mais ampla, coincidindo com a luta e com a vida.

Ainda que compreenda que há outras formas educativas, construídas em experiências sociais e políticas, o MST luta por escolas sediadas nos acampamentos e assentamentos, visando garantir o direito à escolarização das crianças e dos jovens. Nesta perspectiva, constituiu-se um movimento nacional de luta por uma educação básica do campo, articulado por diversas organizações e movimentos sociais.

[...] a proposta é pensar a Educação do Campo como processo de construção de um projeto de educação dos trabalhadores e das trabalhadoras do campo, gestado desde o ponto de vista dos camponeses e da trajetória de luta de suas organizações. Isto quer dizer que se trata de pensar a educação (política e pedagogia) desde os interesses sociais, políticos, culturais de um determinado grupo social; ou trata-se de pensar a educação (que é um processo universal) desde uma particularidade, ou seja, desde sujeitos concretos que se movimentam dentro de determinadas condições sociais de existência em um dado tempo histórico. (CALDART, 2003, p. 43).

Assim, a partir da Primeira Conferência Nacional por uma Educação Básica do Campo, passou-se a usar a expressão campo e não mais meio rural, explicitando a importância de abordar o conjunto de pessoas que vivem no e do campo, incluindo camponeses, quilombolas e indígenas, dentre outros. 
O documento é composto por 19 reivindicações, entre elas, a implementação de programas de formação para os educadores do campo; ampliação da educação de jovens e adultos; garantia da educação infantil e da educação fundamental nas comunidades do campo; formação técnica voltada às demandas de capacitação dos trabalhadores do campo; implementação de políticas públicas de valorização profissional dos educadores do campo; implantação de bibliotecas, brinquedotecas, salas de leitura, salas de informática com acesso à internet nas escolas do campo; criação de secretaria ou coordenação da educação do campo no Ministério da Educação; criação de política de financiamento para a educação do campo, em todos os níveis.

Vale ressaltar que as Diretrizes Operacionais para a Educação Básica do Campo, de 2001, representam uma conquista no âmbito das políticas públicas. Elas foram provocadas no artigo 28 da LDB e propõem medidas de adequação da escola à vida do campo. Reunida em Brasília, entre 26 e 29 de novembro de 2002, a Articulação Nacional por uma educação do campo redigiu, em sua declaração, um conjunto de propostas de ação, que se tornaram uma importante referência para o desenvolvimento de políticas públicas de educação do campo.

As diretrizes operacionais para educação nas escolas do campo, a Resolução CNE/CEB 1, de 03 de Abril de 2002, reconhece o campo como espaço de vida social com toda sua diversidade. Essas diretrizes constituem

[...] um conjunto de princípios e de procedimentos que visam adequar o projeto institucional das escolas do campo às Diretrizes Curriculares Nacionais para Educação Infantil, o Ensino Fundamental e Médio, a Educação de Jovens e Adultos, a Educação Especial, a Educação Indígena, a Educação Profissional de nível Técnico e a Formação de Professores em Nível Médio na modalidade Normal. (RESOLUÇÃO CNE/CEB 1, de 03 de Abril de 2002).

\section{Conforme o exposto nas Diretrizes Operacionais}

[...] a educação do campo tratado como educação rural na legislação brasileira, tem um significado que incorpora os espaços da floresta, da pecuária, das minas e da agricultura, mas os ultrapassa ao acolher em si os espaços pesqueiros, caiçaras, ribeirinhos e extrativistas. (RESOLUÇÃO CNE/CEB 1, de 03 de Abril de 2002).

Ou seja, a Educação Básica do Campo é um nome dado a um movimento nacional que visa mobilizar os povos do meio rural para construção de políticas públicas específicas que garantam o direito à educação no campo, e também contribuir com a reflexão políticopedagógica sobre as práticas educativas que se desenvolvem vinculadas à realidade e as lutas sociais desses povos ${ }^{4}$.

A educação popular se concretiza por possuir uma dimensão coletiva, porque são grupos, comunidades, categorias e outras formas associativas, que buscam juntos a participação na sociedade e traz em seus pressupostos a ideia de um projeto sócio-político, no qual pressupõe uma educação pública para os povos do campo.

Este é um dos principais objetivos presentes na proposta de implantação e implementação de escolas nos assentamentos. Isto tem sido objeto de luta por parte dos trabalhadores rurais: a luta pela conquista da escola, para que se apropriem dos conhecimentos que lhes permitirão ter acesso às novas tecnologias e disputar a hegemonia 
da sociedade. Este aspecto tem instigado um questionamento constante sobre a própria escola.

[...] não é possível compreender o sentido da experiência de educação no e do MST se o foco de nosso olhar permanecer fixo na escola. Somente quando passamos a olhar para o conjunto do movimento, e com a preocupação de enxergá-lo em sua dinâmica histórica (que inclui a escola), é que conseguimos compreender que educação pode ser mais que educação, e que escola pode ser mais que escola. (CALDART, 2000, p. 143).

O conceito de educação do campo nasce de uma concepção de educação que pressupõe a luta pela democratização da sociedade brasileira e o reconhecimento dos educandos como sujeitos de história e de direitos. Nesse sentido, não basta ter escolas no campo; é preciso ter escolas do campo, comprometidas com as lutas, os desafios, a história e a cultura de sua população. O desafio está em desenvolver projetos político-pedagógicos que permitam construir essa identidade e que promova a humanização.

Nesta perspectiva, a escola reconstrói o seu domínio político, haja vista que cria novos espaços deixando à margem saberes concebido como opacos porque alienantes e sem significados. Sob essa ótica, a escola passa a ser pensada como o espaço da possibilidade de reconstrução social, cultural e humana, como esperança concreta de que o acesso a esta instituição oficial venha ensejar uma educação que possa favorecer a liberdade interpretada no meio rural como inserção sócio-profissional dos filhos dos trabalhadores do campo; um saber-cultura, representando um ato de emancipação, concretizando um afastamento real de suas origens camponesas, sem perder de vista o elo com identidades constituídas e construídas historicamente no cotidiano familiar, nas lutas dos movimentos sociais, no trabalho e na escola.

Trata-se de equilibrar as exigências de uma formação de caráter universal, associada às peculiaridades regionais da cultura local. Assim, "[...] desnaturalizar e historicizar o currículo existente é um passo importante na tarefa política de estabelecer objetivos alternativos e arranjos curriculares que sejam transgressivos da ordem curricular existente". (MOREIRA; SILVA, 1994, p. 31).

Para Furtado e Souza (1998), trata-se de uma nova postura analítica como indício de ruptura, interpretada no cerne da escola rural como uma ação inovadora, organizada a partir das possibilidades de atuação dos professores, ou seja, uma ordenação cultural exercida nos limites do espaço pedagógico a partir da ação de atores locais e da participação popular, que espera vigilante, a ocasião e a possibilidade de se manifestar, imprimindo outra racionalidade aos saberes a serem instituídos na perspectiva de desenvolvimento.

A discussão curricular, articulada na ótica do espaço rural, recoloca a questão agrária e a escolarização como aspectos vinculados às lutas travadas dos movimentos populares, diante da crise instalada pela sociedade capitalista, onde se registra o não acesso a terra como propriedade junto com uma escolarização em que se perpetua o discurso da ordem diante dos conflitos e desafios, que requerem tanto uma formação crítica quanto ensinamentos científicos necessários à superação da realidade existente.

Esta dimensão indica a construção de princípios voltados para a transformação, a serem assumidos pelos sujeitos do campo, onde a questão agrária passa a ser interpretada como da classe trabalhadora, presente em todos os espaços educativo-produtivos, redefinindo um cenário de luta pela terra, via reforma agrária. Nesse âmbito, também emerge a luta por uma educação em seu conceito mais amplo, que extrapole a esfera da 
escola pública e avance em direção aos movimentos emergentes não representados pelo currículo oficial; um conteúdo que represente e simbolize a resistência e a luta por causas sociais e emancipatórias.

É, portanto, nesta perspectiva que se insere o debate acerca da educação nas áreas de assentamentos e que nos levam à esta reflexão sobre a experiência da "educação no campo" no assentamento do Rio Bonito do Iguaçu, localizado no oeste paranaense.

\section{Trajetória de educação dos assentamentos no município de Rio Bonito do Iguaçu5}

No Paraná, já ocorreram muitos conflitos pela posse da terra. O próprio surgimento do MST é decorrente disso. Seu início foi marcado por inúmeros conflitos violentos, como aconteceu em 1980 entre camponeses sem terra, polícia militar e jagunços da Empresa Giacometti Marodim S.A., empresa proprietária de um latifúndio de 95.000 ha. localizado nos municípios de Quedas do Iguaçu e Laranjeiras do Sul, no Oeste do Paraná. Após a ocupação da área por Sem Terra, seus proprietários enviaram jagunços para expulsar os ocupantes, que resultou em várias mortes.

Em 1981, havia inúmeras pessoas que tinham perdido terra, emprego, casas e muitos eram atingidos da Itaipu binacional. A CPT organizou estas famílias e começou a cadastrar outras que também tinham perdido ou que haviam sido expulsas da terra e estavam interessadas em lutar por ela. Em 1982, vários movimentos de resistência dos camponeses eclodiram, dentre eles o dos Agricultores Sem Terra do Oeste do Paraná (MASTRO) apoiado pela Associação de Estudos, Orientação e Assistência Rural (ASSESSOAR) ${ }^{6}$.

Até 1993, Rio Bonito do Iguaçu era distrito de Laranjeiras do Sul - Região Oeste do Paraná. Até esta época existiam quatro escolas rurais municipais que respondiam à secretaria de educação da região de Laranjeiras do $\mathrm{Sul}^{7}$. Esta região era nova para os colonizadores que, durante os primeiros anos, enfrentaram muitas adversidades. As pessoas não contavam com nenhum tipo de conforto, era a dureza do trabalho na terra e dela tirar o sustento. Neste contexto, a escola foi assumindo maior importância na medida em que as crianças iam crescendo, estavam desocupadas e eram analfabetas. Contudo, as mudanças eram lentas.

Eram tempos difíceis, as salas de aula estavam cheias, só se contava com a boa vontade do professor, que geralmente não tinha muito acesso a material didático. As aulas eram dadas por quem tinha um pouco mais de instrução, ou seja, sabia ler, escrever e contar - era o que bastava para poder ensinar as crianças carentes de tudo.

Após inúmeras tentativas frustradas, em 14 de dezembro de 1991, acontece o plebiscito em que a população pôde expressar seu desejo favorável à emancipação políticoadministrativa. Porém, só em 19 de março de 1992, o governador Roberto Requião assinou o decreto e reconheceu o novo município que passou a se chamar Rio Bonito do Iguaçu, por ser banhado grande parte de suas terras pelas águas do Rio Iguaçu. Em três de outubro de 1992, os eleitores elegeram o primeiro prefeito, Sezar Augusto Bovino.

As escolas eram multisseriadas e uma só professora trabalhava com até quatro séries na mesma sala, preparava a merenda, cuidava da limpeza, reunia pais e atendia a saúde dos alunos. A professora não tinha acesso a livros nem a cursos de atualização. Com a emancipação do município, o prefeito propôs centralizar as escolas rurais numa única, com mais espaço físico e com uma professora para cada série.

Nesse ano, também ocorreu a centralização das escolinhas do centro do município e foram feitos novos acordos com o governo paranaense para ampliar a oferta de ensino de 
$5^{\mathrm{a}}$ a $8^{\mathrm{a}}$ série. Além disso, em 1994, as professoras que atuavam no município passaram por concurso público, tornando-se servidoras municipais.

A partir de 1996, o quadro de escolas do então Município de Rio Bonito se altera devido à presença dos Sem Terra oriundos de todas as regiões do país e até mesmo do Paraguai, que buscavam a conquista da terra pela primeira vez ou vinham de acampamentos desfeitos pela justiça. Acamparam às margens da rodovia PR 158 neste mesmo ano e permaneceram por um longo tempo mapeando a região com vistas à ocupação. Na madrugada de 17 de abril de 1996, os sem-terra levantaram seus barracos e partiram em direção a Fazenda Giacomet Marodim, ali ficaram e armaram seus barracos, num lugar posteriormente denominado "Buraco", próximo à ponte do Rio Xagú.

Cerca de três mil e quinhentas famílias permaneceram por oito meses, sendo que algumas crianças em idade escolar frequentaram as Escolas Municipais de Rio Bonito do Iguaçu. Do "Buraco", as famílias deslocaram-se para o portão da fazenda, e, algum tempo depois, para a sede da fazenda, que foi denominada comunidade Primeira Conquista e formaram o Assentamento Ireno Alves.

O Assentamento Ireno Alves dos Santos tinha em torno de 1500 famílias, pois algumas já haviam recebido seu lote. Nesse local, foi criada a primeira escola no ano de 1997, denominada Escola Rural Municipal Vanderlei das Neves. Esta escola atendia 896 alunos de $1^{\mathrm{a}}$ a $4^{\mathrm{a}}$ série divididos, em 27 turmas. As aulas eram ministradas em um barracão. Em 1998, os alunos passaram a estudar no Centro Estudantil Vanderlei das Neves (CEVAN) e na Escola José Alves dos Santos, criada no mesmo local.

Com o passar do tempo, as famílias que moravam nesse assentamento foram se subdividindo em função de algumas terem conquistado a terra e outros por ainda continuarem esperando. Assim, umas famílias começaram a mudar para outras áreas e algumas crianças tinham dificuldades de frequentar esta escola. Com isso, aumentam o número de escolas. Na Escola Rural Municipal Chico Mendes na comunidade de Arapongas, atendia de $1^{\mathrm{a}}$ a $4^{\mathrm{a}}$ série. Na comunidade, conhecida por Centrão, atual Alta Floresta, foi fundada a Escola Rural Municipal Severino da Silva, destinada às comunidades de Juriti, Nova Estrela, Alta Floresta, Campos Verdes, Santo Antonio, também atendendo alunos de $1^{\mathrm{a}}$ a $4^{\mathrm{a}}$ série. No início, funcionou em uma das casas dos guardas da fazenda. A Escola Rural Municipal Irmã Dulce, por sua vez, localizada no Assentamento Ireno Alves dos Santos atendia a comunidade formada pela região de Água Mineral, com crianças de $1^{\mathrm{a}}$ a $4^{\mathrm{a}}$ série e Escolarização de Jovens e Adultos. Havia duas turmas de Jornada Ampliada e uma de Multi-Idade, no total de 210 alunos.

Posteriormente, criou-se o assentamento Marcos Freire, onde também foram criadas a Escola Rural Municipal Paulo Freire, que funcionava na comunidade de Centro Novo, atendendo 60 alunos de $1^{\text {a }}$ a $4^{\text {a }}$ série. Em 1999, mudou-se para também atender a comunidade de Camargo Filho. Em julho, desse mesmo ano, ficou pronta a Escola Sebastião Estevam da Costa, que passou a atender alunos de $5^{\mathrm{a}}$ a $8^{\mathrm{a}}$ série por intermédio dos convênios e parcerias com INCRA e FUNDAPAR e atender, de $1^{\mathrm{a}}$ a $4^{\mathrm{a}}$ série, alunos da Escola Rural Municipal Paulo Freire. A Escola Rural Municipal Hebert de Souza, localizada no assentamento Marcos Freire, atendia a comunidade de Centro Novo de $1^{\mathrm{a}}$ a $4^{\mathrm{a}}$ série.

A educação em Rio Bonito do Iguaçu é marcada pela atuação combinada do poder público, movimentos sociais do campo e a população em geral. O resultado dessas iniciativas foi à formulação de propostas relativamente inovadoras para o desenvolvimento do município e da educação do campo. Em 2006, foi elaborada uma Constituinte Escolar que contribuiu com uma análise histórica da educação do campo, reconheceu sua caminhada e possibilitou "[...] (re)pensar a Escola do Campo [...]. Neste contexto, a escola 
do campo pode vir a ser um lugar concreto de vivências participativas e democráticas, de formação dos sujeitos e exercício da conquista de direitos." (DOSSIÊ MST ESCOLA, 2005, p.2).

De acordo com este documento, a Constituinte Escolar de Rio Bonito do Iguaçu

[...] busca a ampla participação da população, da sociedade civil organizada e do poder público municipal na (re) produção da Escola do Campo, através de debates, estudos e socialização de práticas educativas, o que, por sua vez, produzirão os princípios e diretrizes para Educação do Campo no município. (DOSSIÊ MST ESCOLA, 2005, p.7).

Por meio da participação e do envolvimento da comunidade, pretendia-se ir além da democracia representativa, “(i) Vivenciar uma participação popular capaz de superar a democracia representativa, forjando sujeitos históricos pelo seu protagonismo social” (Idem).

Nesta perspectiva, a ação educativa da Secretaria Municipal de Educação de Rio Bonito do Iguaçu busca a formulação de políticas públicas para o campo, com o objetivo de levar à erradicação do analfabetismo, a formação de professores engajados nas causas do MST e a construção de uma sociedade sem explorados nem exploradores, portanto, para além da cidadania burguesa. A concepção da prática integra uma unidade dinâmica e dialética de conhecimento, contribuindo com o processo de socialização de conhecimentos, buscados na educação popular, tendo em vista a superação da condição existente.

\section{Considerações Finais}

Este estudo possibilitou perceber que, se os movimentos sociais, particularmente o MST e, especificamente, o caso do Rio Bonito do Iguaçu (PR), têm como uma de suas importantes bandeiras a luta pela terra, pela reforma agrária e manutenção do trabalho junto a terra, não descuram da educação como um relevante fator de formação de consciência e de luta pela mudança da sociedade. Nesta perspectiva, o fenômeno educacional deixa de ser entendido como restrito a métodos e repasse de conteúdos formais e procura contemplar a totalidade das relações sociais.

Para os assentados de Rio Bonito do Iguaçu, a educação realiza-se tanto por meio da escola, como pelas marchas, caminhadas, assembleias e lutas, que abarcam desde a participação das crianças, mulheres, da juventude, dos idosos, com o objetivo de construir novas relações e desenvolver novas consciências envolvendo o ato de ler e escrever a realidade e a vida.

Neste contexto, o trabalho do educador é o de propiciar um vinculo orgânico entre os indivíduos e o projeto a formar. Qual seja, a partir do particular, realizar interesses universais. Isto é, pensar a educação no/do campo como processo de construção gestado desde o ponto de vista e do local dos camponeses e de sua trajetória de luta, de sua organização (MST), mas que não se volta exclusivamente para eles - implica superar os interesses particulares e implementar um projeto de educação que contemple os interesses universais, a emancipação de toda a humanidade.

\section{Referências}

ANTUNES, R. Os sentidos do trabalho: ensaios sobre a afirmação e a negação do trabalho. São Paulo: Boitempo, 2001.

CALDART, R. S. A escola do campo em movimento. Currículo sem Fronteiras, v.3, n.1, p.20-81, 2003. 
Petrópolis: Vozes, 2000.

Pedagogia do movimento sem terra: escola é mais que escola.

Educação popular no meio rural: as experiências pedagógicas nas escolas do MST. In: Silva, L. H.; A, J. C. (Orgs.). Reestruturação curricular. Petrópolis: Vozes, 1995.

Educação em movimento: formação de educadoras e educadores no MST. Petrópolis: Vozes, 1997.

DOSSIÊ MST ESCOLA. Caderno Pedagógico N. 1, Texto Base. Documentos e estudos 1990-2001. ITERRA, 2005.

KOLLING, E. J.; Ir. NERY; MOLINA, M. C. (Orgs.). Por uma educação básica do campo. Brasília: UNB, 1999.

KUENZER, A. Z. Pedagogia da fábrica: as relações de produção e educação do trabalhador. 4. ed. São Paulo: Cortez, 1985.

MELO, D. M. de. Subjetividade e gênero no MST: observações sobre documentos publicados entre 1979 e 2000. In: GOHN, M. da G. (Org.). Movimentos sociais no início do séc. XXI: antigos e novos atores sociais. Vozes: Petrópolis, 2003

MOREIRA, A. F B.; SILVA, T. T. da (Org.). Sociologia e teoria crítica do currículo: uma introdução. In: Currículo, cultura e Sociedade. São Paulo: Cortez, 1994

MORISSAWA, M. A história da luta pela terra e o MST. São Paulo: Expressão Popular, 2001.

PEREIRA, J. E. D. Derrubando as Cercas: A educação no Movimento dos Trabalhadores Rurais Sem Terra (Brasil) Currículo sem Fronteiras, v.3, n.1, pp.5-10, Jan/Jun 2003.

RESOLUÇÃO CNE/CEB 1, de 03 de Abril de 2002. Disponível em: www.mieib.org.br/legis/reso_ceb_1_030402.pd Acesso em: 20 ago. 2006.

Secretaria municipal de educação, cultura e esportes. A Constituinte escolar de Rio Bonito do Iguaçu. Caderno pedagógico n. 1 Texto Base.

VENDRAMINI. C. R. Terra, trabalho e educação: experiência sócio-educativas em assentamentos do MST. Ijuí: UNIJUI, 2000.

Notas:

\footnotetext{
${ }^{1}$ Graduada em Pedagogia/Séries Iniciais - Unisinos/RS, Mestre em Política Social - UFMT, Membro do grupo de pesquisa da UFMT "Ciência, Tecnologia e Inovação Tecnológica" o INTEC Cuiabá - MT. E-mail: crpaese@yahoo.com.br

${ }^{2}$ Doutor em História e Filosofia da Educação pela Unicamp, docente dos Cursos de Pedagogia e Mestrado em Educação da Unioeste e líder do Grupo de Pesquisa HISTEDOPR/UNIOESTE/ Campus Cascavel. E-mail: paulinorso@uol.com.br

A Comissão Pastoral da Terra (CPT) foi criada em 1975, o Partido dos Trabalhadores (PT), em 1980 e a Central Única dos Trabalhadores (CUT), em 1983.

${ }^{4}$ O MST participa deste Movimento que começou em 1997.

${ }^{5}$ Rio Bonito do Iguaçu é município desde 19 de março de 1992, numa área de $746 \mathrm{Km} 2$, situado na região Oeste do Estado do Paraná. Sua população é de 19.069 habitantes. Grande parte dos residentes no município é composta por assentados do MST e do MAB (Movimento dos Atingidos por Barragens) (IBGE/CIDADES, 2005).

${ }^{6}$ A Assessoar é uma entidade filantrópica que trabalha com agricultura familiar. Sua origem remonta a meados dos anos 60 do século passado. Foi fundada por jovens do meio rural com apoio da Igreja Católica.

${ }^{7}$ É necessário relatar sua história, pois fazem parte da trajetória de educação de Rio Bonito do Iguaçu.

Recebido em: $\quad 12 / 11 / 11$

Aprovado em: $\quad 05 / 01 / 12$
} 